\title{
Return on Education Using the Concept of Opportunity Cost
}

\author{
Peter Marinič ${ }^{1, *}$ \\ ${ }^{1}$ Masaryk University, Faculty of Education, 60300 Brno, Czech Republic
}

\begin{abstract}
Education is an important part of individual life. Everyone is learning whether realizing it or not. There is pressure for a longer period of formal education due to the growing volume of knowledge and the need to use it in working life nowadays. In connection with new technologies, there is a need for growing population with tertiary education, but there is also a need for a skilled workforce with appropriate vocational training achieved by upper-secondary education. Formal education takes place mainly in the full-time form, which makes it necessary to give up the possibility of earning income from classic employment relationship. Improving employability at labour market and possibility to get higher net income, forces individuals to stay at education for longer time and to sacrifice possible incomes during the time. Therefore, education is analysed as opportunity costs and the payback period of education is assessed with respect to the increase in the net mean income. The results of the analysis carried out according to data from the Member States of European Union show significant differences in the opportunity cost and in the return on education as investment, both, for tertiary education and for upper-secondary education.
\end{abstract}

\section{Introduction}

Education is important activity influencing everyone, influencing ability of perceive the environment adequately to the stimuli from the environment, to make decisions in everyday situations, but also to create long-term plans, achieve work and personal success. It also shapes the society. Education is a prerequisite for development of society, whether in the field of innovation, technology, production of wide variety of products or services, thus educational society, but also in the development of civil society, due to creating preconditions for development of democratic institutions, freedom, environment protection, social responsibility, solidarity and belonging $[1,2]$.

As the amount of knowledge increases during the time, there is also need to ensure the transmission of ever-increasing amount of curriculum in teaching process. This creates pressure on the intensity of educational process at each educational level, but also increases demands on the length of the educational process. This tendency pushes to differentiate and specialize education, education institutions and the education system, and creates wide range of different types of schools, especially at upper secondary and tertiary level.

\footnotetext{
* Corresponding author: marinic@ped.muni.cz
} 
The changes in the educational structure of active population, thus people from 15 to 64 years of age, according to the completed educational level is in figure 1. There is proportion of primary, upper-secondary, and tertiary education displayed for analysed countries, mostly the Member States of European Union. The educational structure of countries differs, but there is clear tendency of increasing proportion of people with completed higher than primary education when comparing the situation in 2008 to 2018.

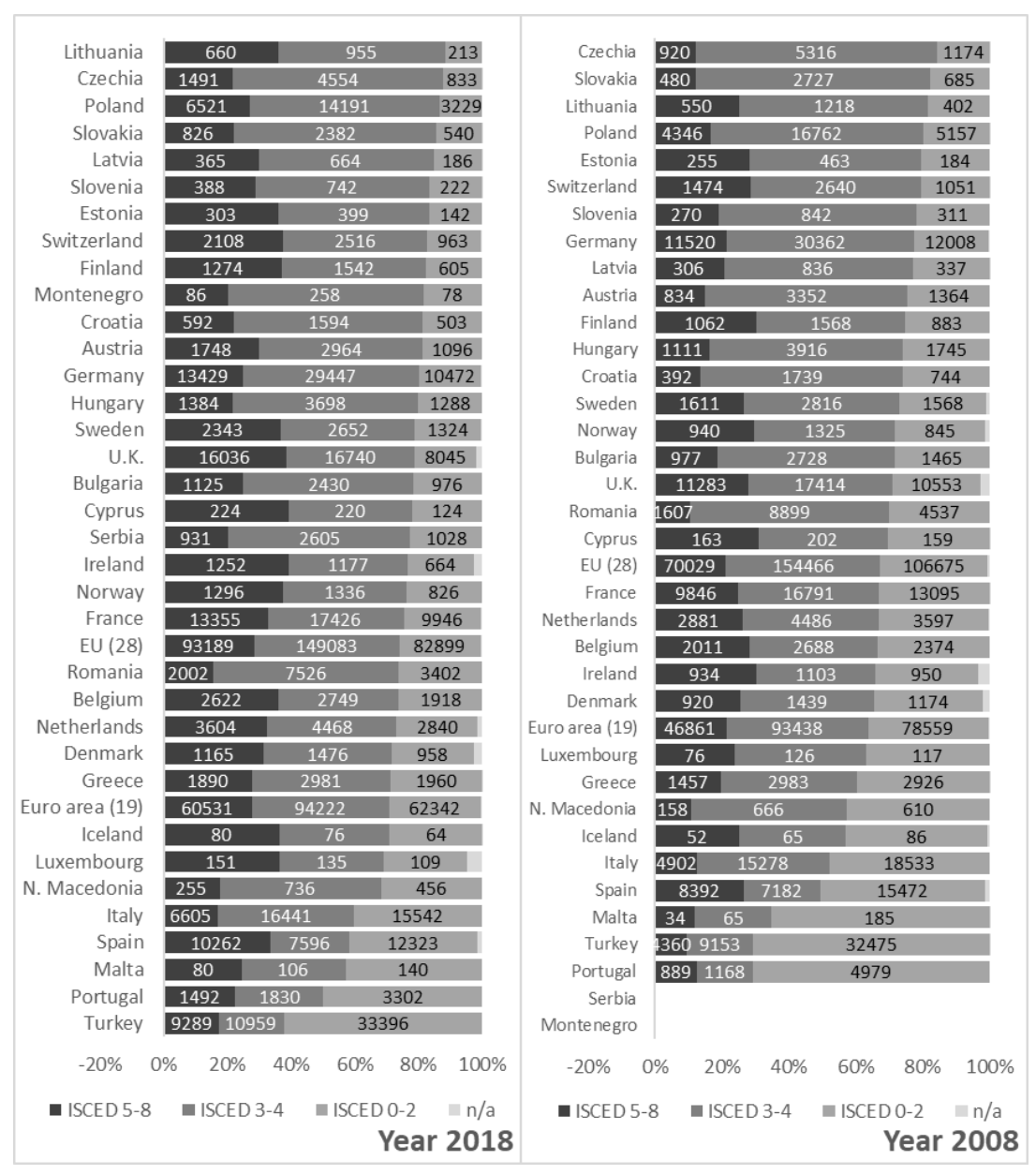

Fig. 1. Structure of the population (15-64 years) according to completed education level.

\section{Methodology}

All these aspects are considered by individuals when choosing their educational paths. This choice usually takes place at the end of primary education level, when choosing the next upper secondary education level. However, it is not uncommon for future direction of educational path to be decided in early childhood, or, conversely, that even at the end of primary education level or even at the end of upper secondary education level, in case of choosing the general education orientation, it is not definitely decided.

Many variables affect the decision-making process about educational path. It could be family traditions and preferences of certain professions, the possibility of achieving social status associated with certain professions, or perspective of promising earnings associated 
with the chosen profession. The analysis of the justification of the last-mentioned motive is the aim of the paper [3].

There are several approaches to the analysis of the economic effects of the education. The classical approach to assessing the impact of education on individual's economic situation typically focuses on the completion of tertiary education level. The approach to these impacts has been developing for several decades and there are studies from international organizations as well [4-10]. The consider particularly the effect of education on the potential of higher earnings and lower unemployment, respectively higher employability, of graduates of tertiary education, in various lengths of evaluations. Thus, there is a certain volume of educational benefits expressed by money. The studies also consider the need to devote certain time to the education process, considered as costs associated with education, even in relation to the loss of earnings from employment in the labour market due to devoting to education.

The paper uses this approach of opportunity costs in a simple way, but analysis not only the tertiary education but also the upper-secondary education is provided. The time spend in the upper-secondary and tertiary education is taken as the loss of opportunity to earn mean net income from the employment with adequate educational level. Thus, for the uppersecondary education the net mean income of the primary educated employee is considered for the 4 years period assumed as the proper time for upper-secondary education process. And for the tertiary education the net mean income of upper-secondary educated employee for the 5 years period was assumed.

The opportunity costs were then compared to the difference of net mean incomes of the appropriate educated employees, thus the difference between the primary educated and upper-secondary educated employee and the difference between the tertiary and uppersecondary educated employee. The return rate is the result of this approach which can be marked as the return on investment in education.

\section{Economic effects of education - Data and its analysis}

In the analysis the net mean income according to completed education level is used. The first part of table 1 presents the results of this variables in the year 2008 and 2018. The typical structure of the net mean incomes is increasing with the increase of completed education level, which is understandable. Interestingly, although net mean income is rising in many countries, it is possible to identify EU Member States where the net mean incomes has fallen. The impact of economic crisis after 2008 has probably manifested itself, and it has affected some EU countries quite significantly.

Second part of the table 1 shows the results of the analysis of opportunity costs and return rate for upper-secondary education. It shows that there is higher net mean income of the upper-secondary educated employee that that with the completed primary education. The opportunity costs of upper-secondary education vary in the unit tens of thousands and the return rate in units of per cent. The average opportunity costs of upper-secondary education for European union are $€ 61,048$ with the return rate $4.99 \%$ in 2018 . The highest return rate is for Bulgaria $(20.85 \%$ with OC $€ 10,028)$ and Romania $(16.73 \%$ with OC $€ 9,312)$, the lowest return rate is for Iceland (1.41\% with OC €164.444) or Finland (1.77\% with OC €97,460).

The third part of the table shows the results for tertiary education using the same approach. There is also positive difference in net mean income for all countries. The average opportunity costs in European Union are $€ 91,545$ with the return rate $9.25 \%$ in 2018. The highest return rate is in Romania $(17.07 \%$ with OC $€ 19,430)$ and Bulgaria (15.8\% with OC €22,990), the lowest for Sweden $(2.17 \%$ with OC $€ 239,655)$. 


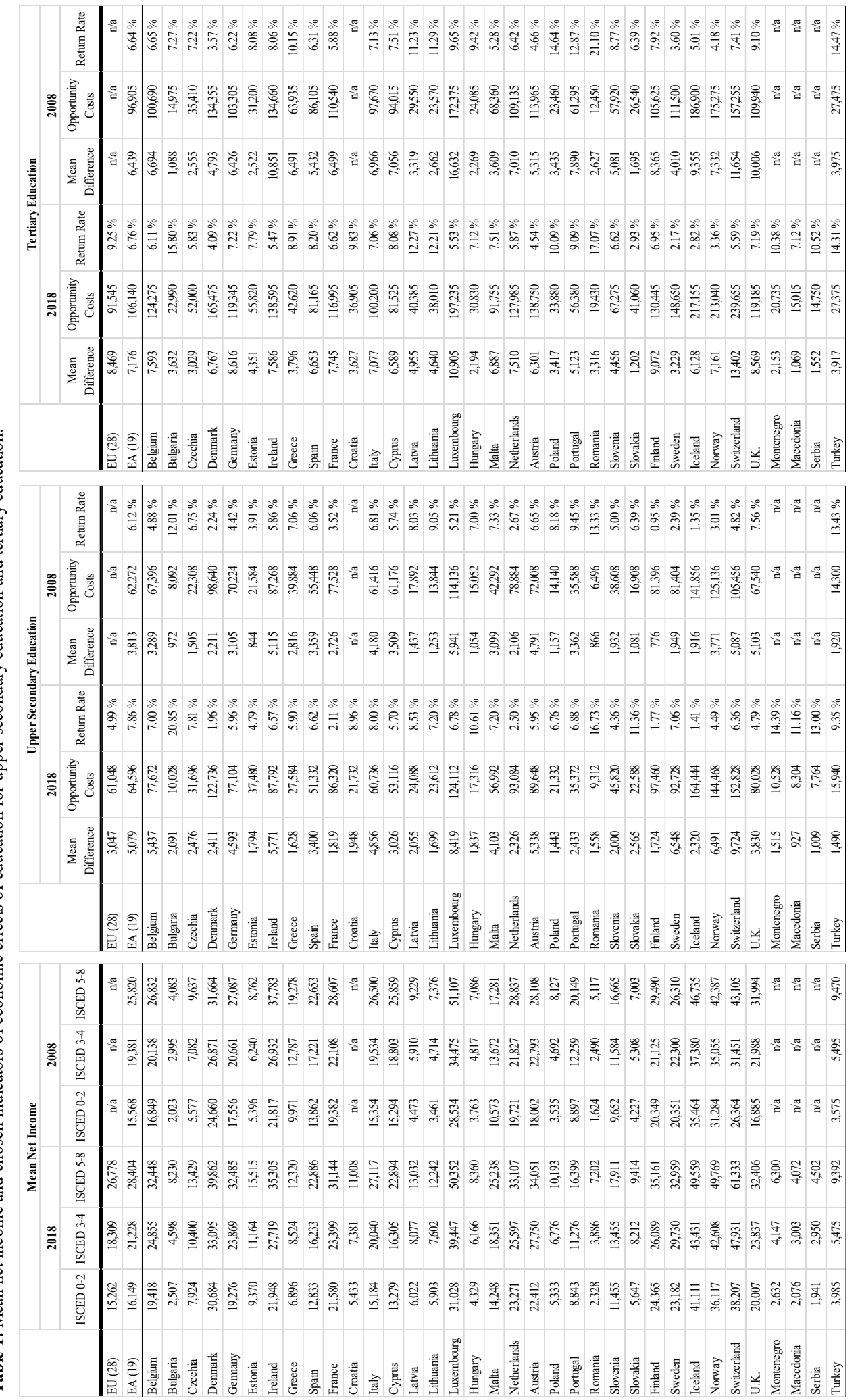




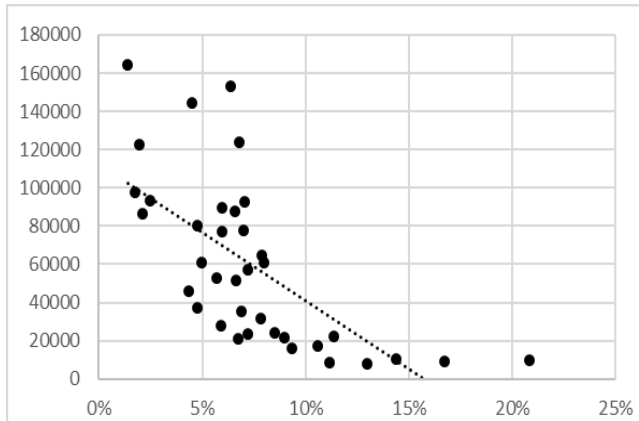

ISCED 3-4 | Year 2018

Opportunity Costs vs. Return Rate

$y=-716130 x+112676$ $R^{2}=0,4455$

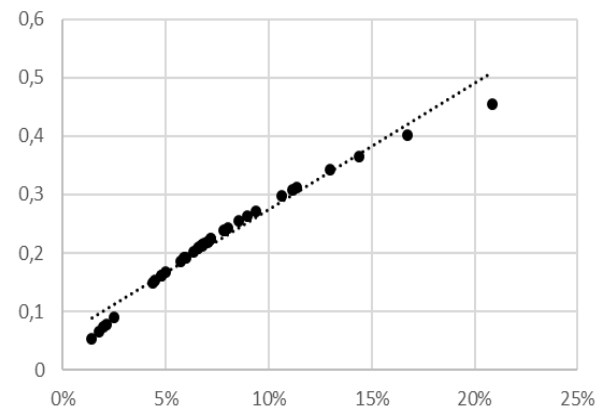

ISCED 3-4 | Year 2018

Mean Net Incomes Ratio vs. Return rate

$y=2,1584 x+0,0579$ $R^{2}=0,9674$

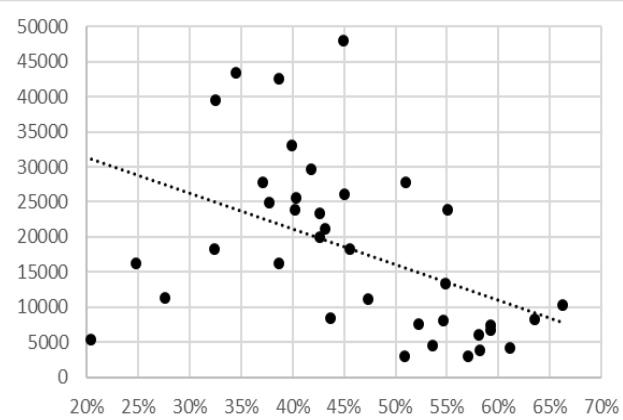

ISCED 3-4 | Year 2018

Mean Net Income vs. Structure

$y=-50938 x+41544$

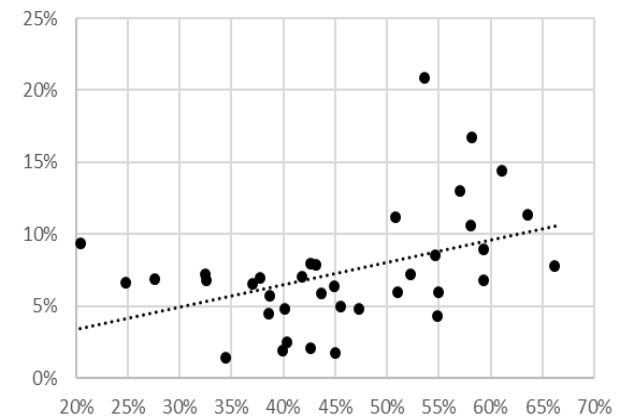

ISCED 3-4 | Year 2018

Return Ratio vs. Strusture $y=0,1556 x+0,0026$ $R^{2}=0,1809$

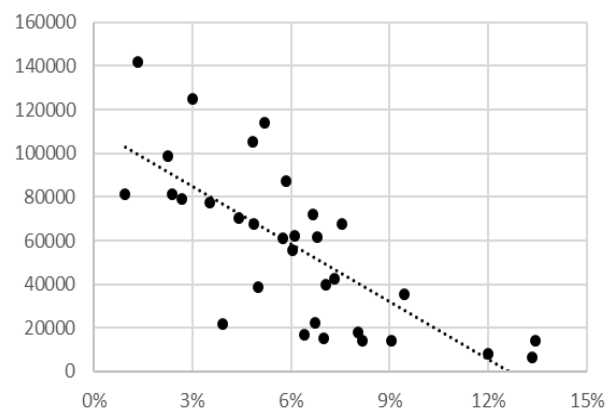

ISCED 3-4 | Year 2008 $y=-879948 x+110979$ Opportunity Costs vs. Return Rate $\quad R^{2}=0,5419$

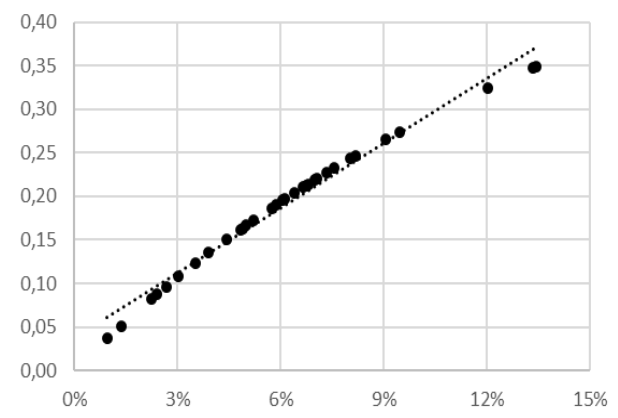

ISCED 3-4 | Year 2008

$y=2,4919 x+0,0368$ Mean net incomes Ratio vs. Return rate $\quad R^{2}=0,9832$

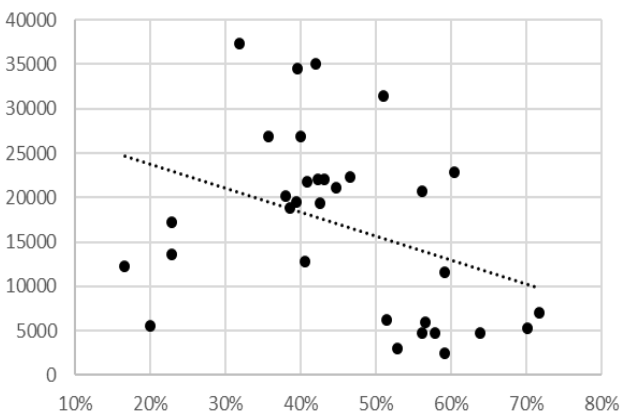

ISCED 3-4 | Year 2008

Mean Net Income vs. Structure

$y=-26791 x+29048$

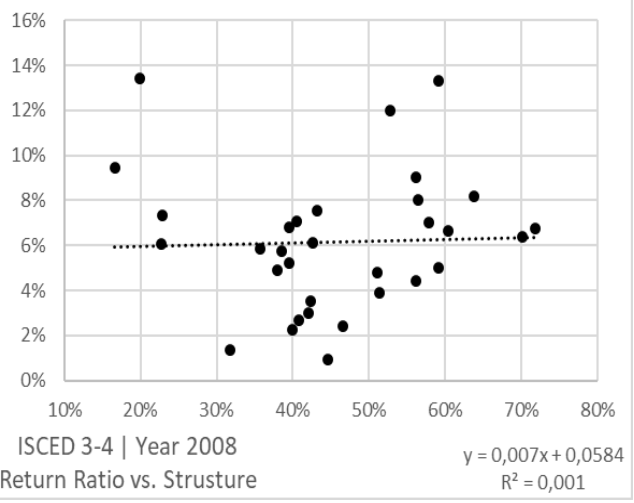

Fig. 2. Relationship between indicators of economic effectiveness of upper secondary education. 


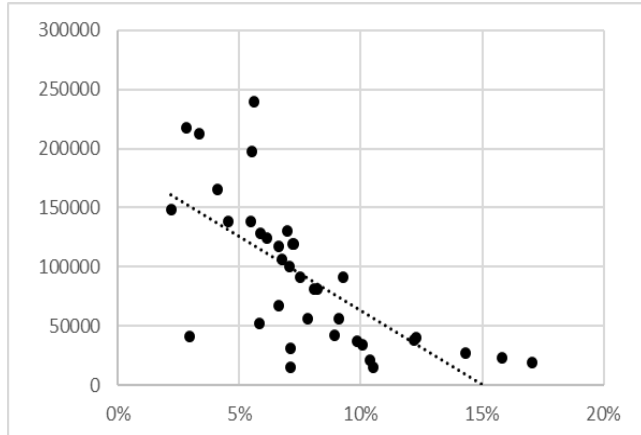

ISCED 5-8 | Year 2018

Opportunity Costs vs. Return Rate

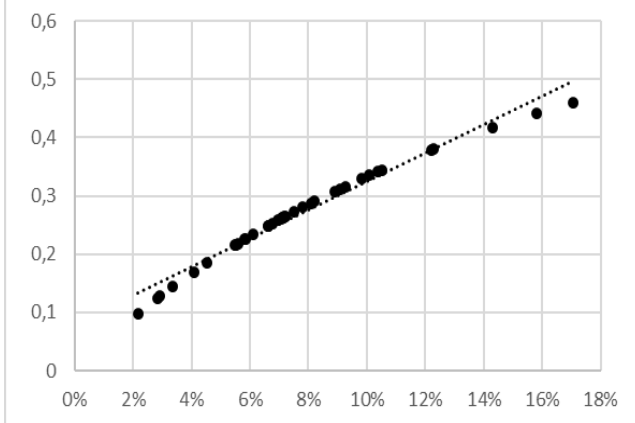

ISCED 5-8 | Year 2018

Mean Net Income Ratios vs. Return rate

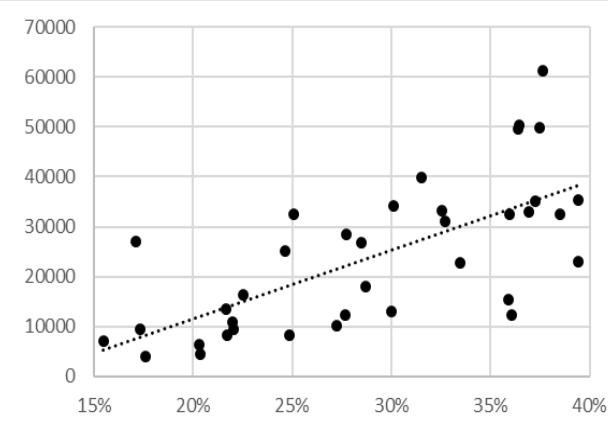

ISCED 5-8 | Year 2018

Mean Net Income vs. Structure

$y=138617 x-16244$ $R^{2}=0,4778$

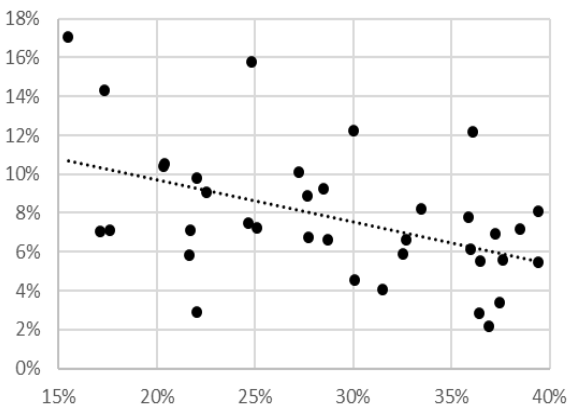

ISCED 5-8 | Year 2018

Return Ratio vs. Strusture

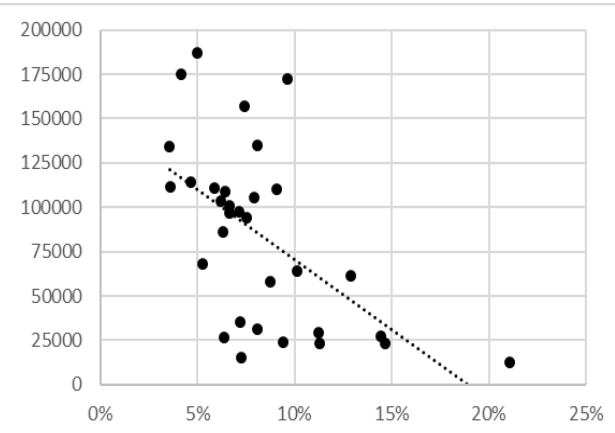

ISCED 5-8 | Year 2008 Opportunity Costs vs. Return Rate $y=-791493 x+149712$

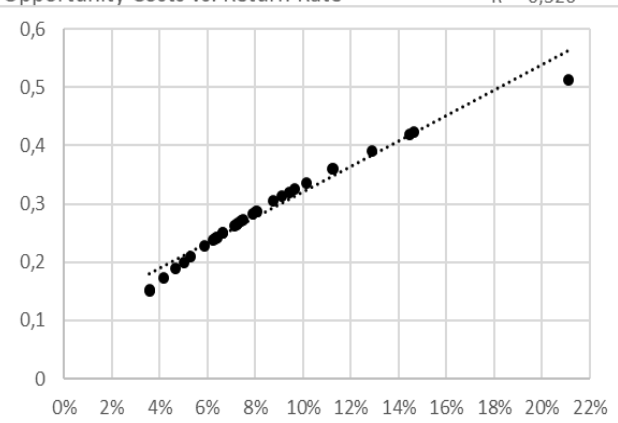
ISCED 5-8 | Year 2008

$y=2,1826 x+0,102$ Mean Net Income Ratios vs. Return rate $\quad R^{2}=0,9683$

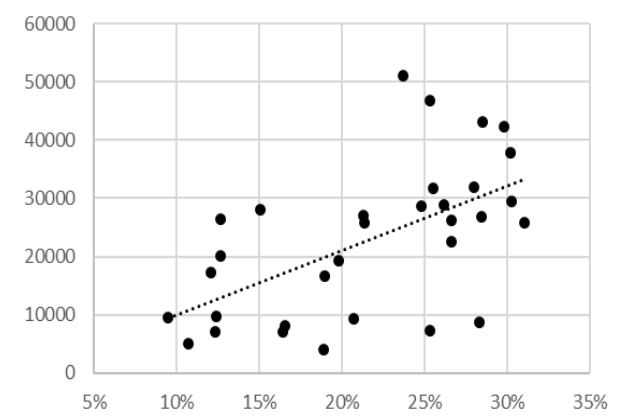

ISCED 5-8 | Year 2008

Mean Net Income vs. Structure

$y=110675 x-1045,5$ $R^{2}=0,3331$

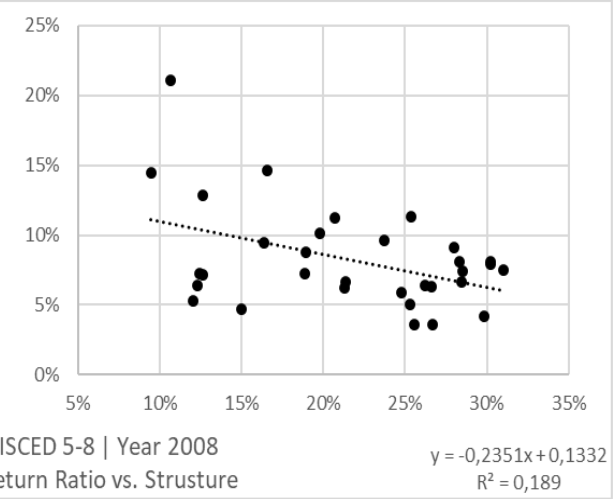

Fig. 3. Relationship between indicators of economic effectiveness of tertiary education. 
Since the return rate is related to opportunity costs and net mean income difference by its construction, figures 2 and 3 provide a closer analysis of this relationship. In addition to the above relations, the relation to the educational structure and the volume if net mean income of the examined group is also assessed. The relation between return rate and opportunity costs, both for upper-secondary education and for tertiary education, is inversely proportional, where logically the lower the opportunity costs the higher the return rate and vice versa. There seems to be no relationship between the return rate and the educational structure in terms of the share of the educational level group and the total active population in both educational levels.

Quite interesting could be the relationship between the net mean income and the education structure. Although no direct causality can be deuced from the analysis, is can be assumed, that the higher net mean income attracts the individuals to tertiary education and as the proportion of tertiary educated employees rise, the proportion of the upper-secondary educated employees stagnates or decreases, it pushes up the net mean income.

\section{Discussion of results - limitations and implications}

The analysis is based on some simplifications. The time needed for obtaining a certain level of education has not been differentiate between countries and has not consider the wide range of options for passing through the education system. The whole period of education was taken as opportunity costs, although the study load of individual education field and levels differ, and thus the possibilities of performing paid employment during studies, which were not considered at all, differ. It was also abstracted from inflation and the changes in the net mean income structure over time, as some other analysis consider [4-9].

However, the aim of the analysis was to point out the possibility of a simple assessment of the economic effectivity of education. The benefit is in the effort to implement not only tertiary education analysis but also upper-secondary education approach. Given the initiative Industry 4.0, which often mention the need for highly educated employees, the importance of tertiary education is emphasized, but the need for skilled workers with uppersecondary education is unfortunately neglected [11-14].

\section{Conclusion}

Education is important part of each of our lives. Its importance is in transfer of information, knowledge, and skills from generation to generation, in developing innovation and creativity, or formation of civil society. Education also contributes to development of individuals, to creation and maintenance of social status and to increase of potential future earnings.

Education is also connected with the need to make efforts to achieve and increase a certain level of education. Thus, it is associated with certain costs that must be expend. These costs can be understood either as direct costs associated with education, such as school fees or the need to purchase of school supplies, or as indirect costs for sacrificed opportunities, such as transformation of leisure time into learning time, or scarification of job opportunities.

Analysis of economic effectiveness of education used in paper is based on such opportunity costs of education. The net mean income of primary educated employees represents the opportunity costs of upper-secondary education and the net mean income of upper-secondary educated employees represents the opportunity costs of tertiary education. On the other hand, the increase in earning due to higher education, thus the net mean income difference between education levels, should replace those opportunity costs. 
The analysis shows big differences in opportunity costs of education in Member States of European Union and in return rate as well. The values vary from $1.77 \%$ for Finland with opportunity costs $€ 97,460$ to $20.85 \%$ with opportunity costs $€ 10,028$ for Bulgaria in the case of upper-secondary education. In the case of tertiary education values vary from 2.17 $\%$ for Sweden with opportunity costs $€ 239,655$ to $17.07 \%$ with opportunity costs $€ 19,430$. These values imply the payback period of less than 5 years to more than 50 years.

The relationship of the return rate to other variables was also analysed. The results show, besides directly proportional relationship between return rate and net mean income ratio, ratio between two considered education levels, also the inversely proportional relationship between the opportunity costs and return rate. Relationship between return rate and educational structure has not been demonstrated. Last relationship analysed did not include the opportunity costs or return rate, the relationship between the net mean income and the educational structure has been examined instead. Different proportional relationship has been identified for upper-secondary education ad for tertiary education.

\section{References}

1. Santiago, P., Tremblay, K., Basri, E., \& Arnal, E. Tertiary education for the knowledge society : volume 1. OECD Publishing (2008).

2. Santiago, P., Tremblay, K., Basri, E., \& Arnal, E. Tertiary education for the knowledge society : volume 2. OECD Publishing (2008).

3. Schomburg, H.,Teichler, U. The educational path and attainments. Springer (2006).

4. Becker, G. S. Human Capital. Columbia University Press (1964).

5. Urbánek, V. Vzdělání a lidský kapitál (2005).

6. Boarini, R., \& Strauss, H. What is the private return to tertiary education : New ecidence from 21 OECD countries. OECD Journal : Economic Studies. http://ssrn.com/abstract=1860961 (2010).

7. OECD. Education indicators in focus : What are the returns on higher education for individuals and countries ? doi : 10.1787/22267077 (2012).

8. Beblavý, M., Lehouelleur, S., Maselli, I. How returns from tertiary education differ by field of study :Implication for policy-makers and students. CEPS, 2015.

9. Krajnakova, E., Pilinkiene, V., Bulko, P. Determinants of economic development and employability of higher education institutions graduates. Inzinerine EkonomikaEngineering Economics. 31, 2020. doi : 10.5755/j01.ee.31.2.24751.

10. Marinič, P., \& Pecina, P. Is tertiary education worth it ? INTED2021, (2021) doi : 10.21125/inted.2021.1607.

11. Pecina, P., \& Sládek, P. Fourth industrial revolution and technical education. INTED2017, (2017) doi : 10.21125/inted.2017.0621.

12. Záthurecký, V., Marinič, P. (2019). Industry 4.0 - Analysis of the economic development in the chosen European countries. ISCSS2019, (2019) doi : 10.21125/inted.2021.1607.

13. Grenčiková, A., Kordoš, M., Navickas, V. The impact of Industry 4.0 on education contents. Verslas Teorija ir Praktika. 22, (2021). 10.3846/btp.2021.13166.

14. Marinič, P., Pecina, P. Industry 4.0 - Relationship between capital equipment and labour productivity. HED2021. doi : 10.21125/inted.2021.1607 (2021). 